06

\title{
Морфология и внутренняя структура тонких пленок оксида олова, газочувствительных к парам этанола при температуре, близкой к комнатной
}

\author{
(C) O.S. Mahdi ${ }^{1,2}$, И.В. Маляр ${ }^{1, \uparrow, ~ В . В . ~ Г а л у ш к а ~}{ }^{1}$, А.В. Смирнов ${ }^{1}$, \\ И.В. Синёв ${ }^{1}$, С.Б. Вениг ${ }^{1}$ \\ ${ }^{1}$ Саратовский государственный университет им. Н.Г. Чернышевского, \\ Саратов, Россия \\ ${ }^{2}$ Al-Muthanna University, Samawah, Iraq \\ ฯ E-mail: imalyar@yandex.ru
}

Поступило в Редакцию 8 декабря 2016 г.

Методом реактивного высокочастотного магнетронного распыления были получены тонкие пленки оксида олова. Было показано, что они обладают газочувствительностью к парам этанола при $38^{\circ} \mathrm{C}$. Измерения морфологии и внутренней структуры скола образцов методами атомно-силовой и сканирующей электронной микроскопии позволили установить, что пленки состоят из наноразмерных зерен стержневидной формы, ориентированных перпендикулярно подложке. Зерна разделены порами, пронизывающими пленку на всю толщину. Было установлено, что распределение зерен по их диаметру является нормальным логарифмическим и имеет несколько центров, которые соотносятся как малые целые числа, что свидетельствует о срастании зерен между собой. Минимальный размер зерна в $6 \mathrm{~nm}$ может соответствовать критическому размеру зародыша при выбранных условиях осаждения пленок.

DOI: 10.21883/PJTF.2017.11.44698.16597

В настоящее время тонкие пленки оксида олова нашли применение в качестве сенсоров для обширного круга различных газов. Широкое распространение они получили благодаря большой ширине запрещенной зоны, каталитической активности и переменной валентности олова, т. е. способности обратимо изменять стехиометрию поверхности в зависимости от кислородного потенциала [1-3].

Также в последнее десятилетие стали появляться работы по созданию газовых сенсоров на основе оксида олова, работающих при ком- 
натной температуре или близкой к ней [4-6], что существенно снижает их энергопотребление и, как следствие, стоимость эксплуатации. Как правило, такие сенсоры обладают нанометровым размером зерна, при этом должно быть обеспечено поступление газа в объем пленки, т.е. необходимо наличие пор.

Одним из способов создания тонких пленок является реактивное магнетронное распыление, которое позволяет управлять стехиометрией и структурой получаемых пленок [7,8]. В работе [9] была предложена модель для магнетронного распыления при одновременном распылении осаждаемой пленки высокоэнергетическими ионами, что позволяет управлять структурой тонких пленок, в частности текстурой, размером зерен и т.п. На основании этой работы в [10] были получены газочувствительные тонкие пленки оксида олова, содержащие нанометровые кристаллиты и поры, с помощью реактивного магнетронного распыления с применением ионного травления в высокочастотном разряде аргона.

Целью данной работы является подробная характеризация морфологии и внутренней структуры пленок оксида олова, в которых газочувствительность наблюдается при температуре, близкой к комнатной.

Были исследованы поликристаллические пленки оксида олова на монокристаллических кремниевых подложках, полученные методом высокочастотного реактивного магнетронного распыления мишени из $\mathrm{SnO}_{2}$, аналогично [10,11].

Измерение рельефа поверхности проводилось методом атомносиловой микроскопии (АСM) с помощью зондовой нанолаборатории NTGRA Spectra (NT-MDT, Россия). Для измерения внутреннего строения образцы раскалывались вдоль кристаллографического направления $\langle 100\rangle$ кремниевой подложки и исследовались с помощью сканирующего электронного микроскопа (СЭМ) типа Mira // LMU (Tescan, Чехия).

Газочувствительность исследуемых образцов оценивалась по изменению сопротивления при напуске в измерительную камеру тестовой пробы. Полученные пленки диоксида олова были высокоомными $R>10 \mathrm{G} \Omega$. Для измерения их сопротивления была использована потенциометрическая схема. Измерительное напряжение составляло $300 \mathrm{~V}$, величина дополнительного последовательно включенного сопротивления составляла $10 \mathrm{k} \Omega$. Измерение падения напряжения на дополнительном резисторе осуществлялось с помощью мультиметра

Письма в ЖТФ, 2017, том 43, вып. 11 
Keithley 2000 (Keithley Instruments, США), имеющего входное сопротивление порядка $10 \mathrm{G} \Omega$. Измерение производилось в непрерывном режиме с периодом $0.5 \mathrm{~s}$.

При измерении газочувствительности измерительная камера сначала продувалась осушенным и очищенным воздухом с содержанием паров воды менее $10 \mathrm{ppm}$, затем в камеру подавалась смесь чистого и прошедшего барботирование через этанол воздуха, затем камера снова продувалась чистым воздухом. Поток газа через измерительную камеру составлял $100 \mathrm{sccm}$. Барботер был термостатирован при $38^{\circ} \mathrm{C}$.

Воздействие паров этанола на сенсор приводило к обратимому снижению его сопротивления (рис. 1,a). Характерное время срабатывания сенсора составляло порядка $8 \mathrm{~s}$. Восстановление сопротивления во время продувки происходило медленно, со скоростью $0.2 \mathrm{M} \Omega / \mathrm{s}$. На pис. $1, b$ представлена концентрационная зависимость отклика сенсора на воздействие паров этанола. Величина отклика рассчитывалась как отношение сопротивления сенсора в потоке сухого воздуха к сопротивлению в потоке паров этанола.

На графике можно выделить два диапазона концентраций: менее $60 \cdot 10^{3} \mathrm{ppm}$ и более. При низких концентрациях чувствительность слабо зависит от концентрации. При концентрациях выше $80 \cdot 10^{3} \mathrm{ppm}$ наблюдается сверхлинейный рост отклика сенсора. Максимальное значение отклика составляет порядка $10^{3}$.

Полученное с помощью СЭМ характерное изображение скола образца (рис. 2,a) демонстрирует неоднородную структуру поликристаллической пленки: зерна стержневидной формы, ориентированные перпендикулярно подложке, и поры. Толщина образцов определялась временем напыления и варьировалась от 85 до $590 \mathrm{~nm}$. Для определения диаметра зерен и размера пор по мере роста пленки были проведены два продольных сечения параллельно поверхности на расстоянии 105 и $490 \mathrm{~nm}$ от подложки и выполнен статистический анализ (рис. 2, b). Было установлено, что распределение зерен по размеру подчиняется нормальному логарифмическому закону, что характерно для поликристаллических материалов [12]:

$$
f(d)=\frac{1}{\sigma d \sqrt{2 \pi}} e^{-[\ln d-\mu]^{2} / 2 \sigma^{2}},
$$

где $d-$ диаметр зерна, $\sigma-$ среднее квадратичное отклонение (дисперсия), $\mu$ - средний диаметр зерна.

5 Письма в ЖТФ, 2017, том 43, вып. 11 

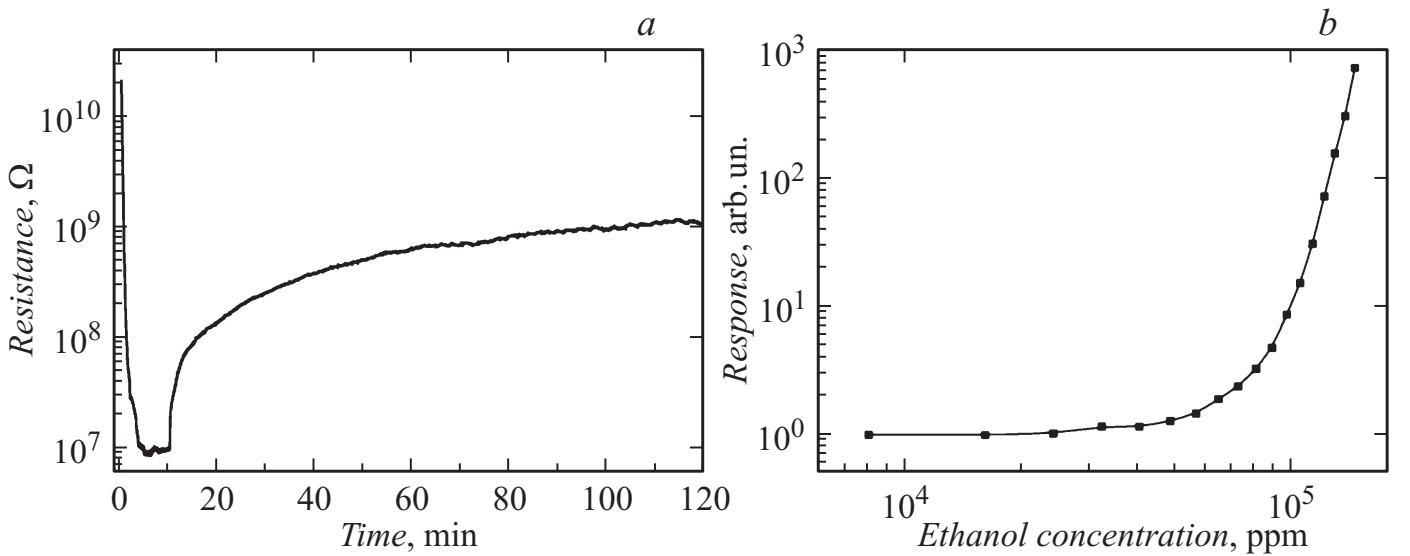

Рис. 1. $a$-изменение сопротивления пленки оксида олова при введении в камеру паров этанола с последующей продувкой чистым воздухом; $b$ - зависимость отклика сопротивления образца на присутствие паров этанола в окружающей атмосфере от концентрации паров этанола 


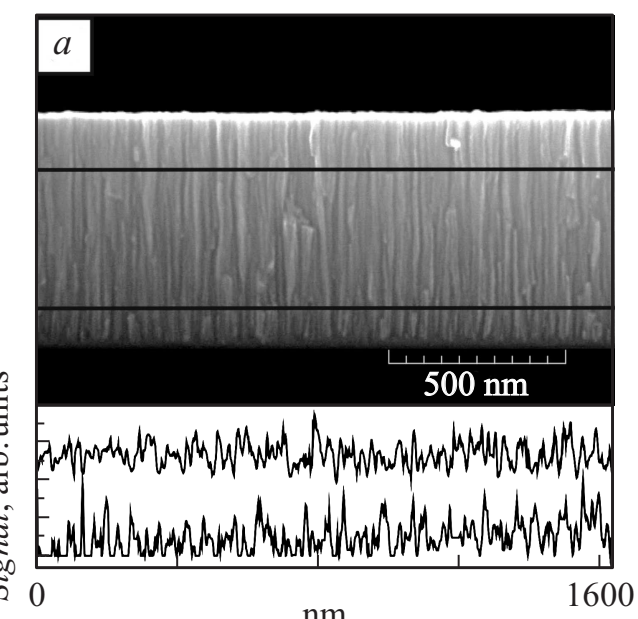

$\mathrm{nm}$ $b$

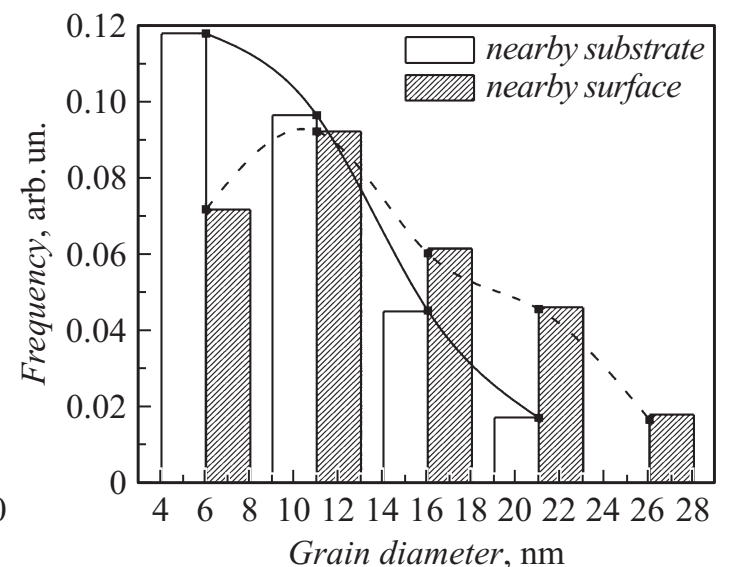

Рис. 2. $a-$ СЭМ-изображение скола образца с продольными сечениями; $b-$ диаграмма и рассчитанное распределение зерен по размеру вблизи подложки и вблизи поверхности для СЭМ-изображения; $c$ - ACMизображение поверхности образца с продольным сечением; $d$ - диаграмма и рассчитанное распределение зерен по размеру для продольных и поперечных сечений на АСМ-изображении. 


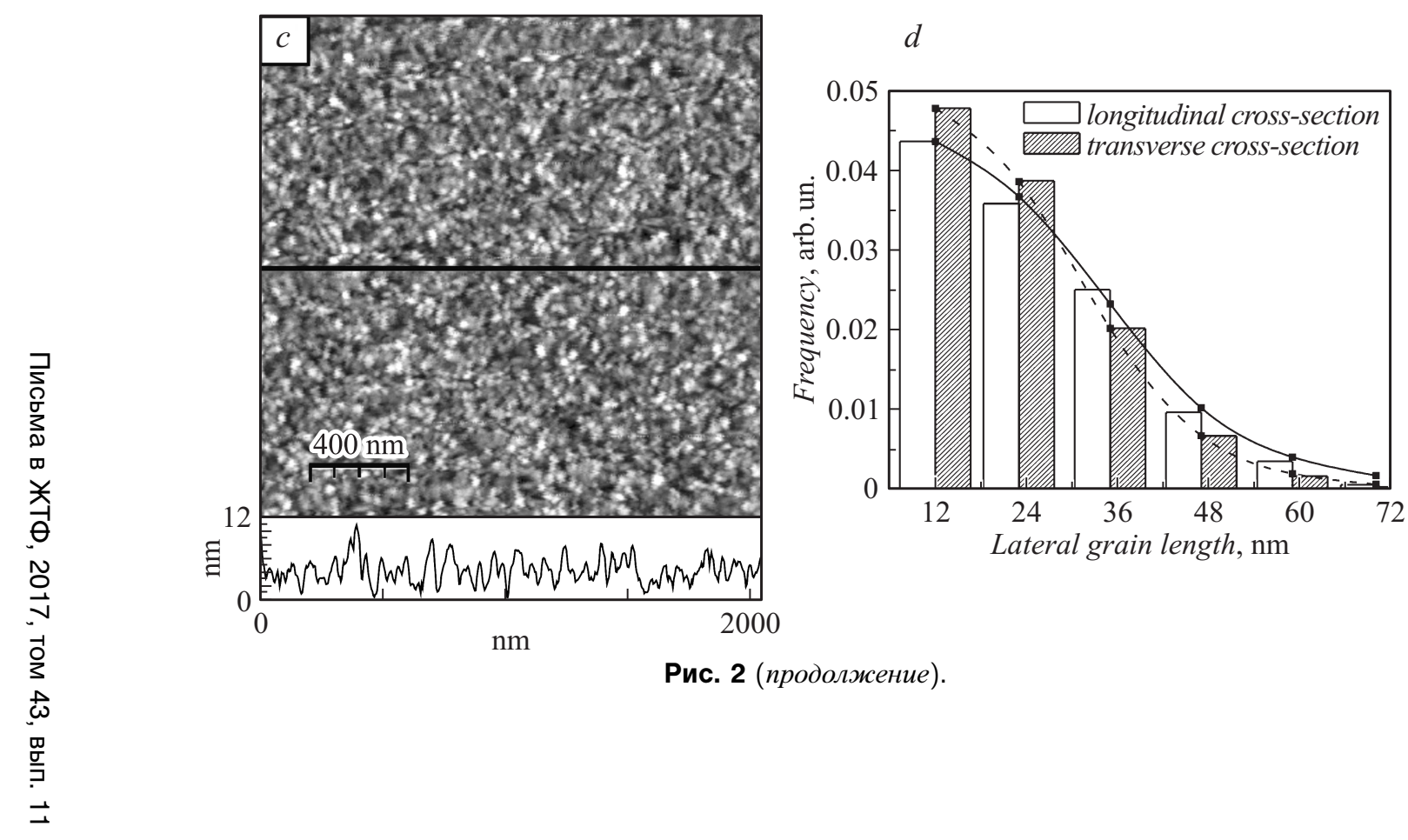


Срастание зерен во время роста пленки приводит к существованию нескольких максимумов (рис. 2,b) и соответственно распределений. Анализ показал, что для сечения вблизи подложки имеется два распределения с центрами 6 и $11 \mathrm{~nm}$ с дисперсиями 2.5 и $4.5 \mathrm{~nm}$ соответственно, а их веса соотносятся как 56.4 на 43.6\%. Так как центры распределений соотносятся как небольшие целые числа $(1: 2)$, то это свидетельствует о срастании малых зерен с образованием крупных. Об этом также может свидетельствовать рост дисперсии для распределения с центром $11 \mathrm{~nm}$, поскольку дисперсии двух распределений складываются с учетом ковариационного члена.

Для сечения вблизи поверхности наблюдается три распределения с центрами 6, 11 и $21 \mathrm{~nm}$ с дисперсией 2, 4.5 и $3 \mathrm{~nm}$ соответственно, а их веса соотносятся как 16.4, 75.9 и 7.7\% соответственно. Центры распределений также соотносятся как небольшие целые числа $(1: 2: 4)$, следовательно, рост диаметра зерен вблизи поверхности также происходит преимущественно за счет срастания. Также увеличивается доля зерен большего диаметра с 43.6 до 83.6

Кроме того, было установлено, что вблизи подложки средний размер пор составляет $10 \pm 5 \mathrm{~nm}$ и уменьшается к поверхности до $5 \pm 2 \mathrm{~nm}$ за счет роста диаметра зерен, что приводит к частичному „зарастанию“ пор.

Изображение поверхности образца (рис. 2,c), полученное с помощью АСМ, демонстрирует неоднородность поверхности, вызванную поликристалличностью полученных образцов. Для определения характерных размеров кристаллитов были проведены сечения (продольные и поперечные) и выполнен статистический анализ (рис. 2, $d$ ). Близость форм рассчитанных распределений для продольных и поперечных сечений позволяет говорить об изотропности ориентации зерен в плоскости образца и ввести усредненное значение латерального размера зерна. Представленные распределения также были аппроксимированы нормальными логарифмическими распределениями с центрами 12 и $23 \mathrm{~nm}$ с дисперсиями 3.5 и $10 \mathrm{~nm}$, а их веса соотносятся как 26.9 и 73.1\% соответственно.

Таким образом, было установлено, что поликристаллические пленки оксида олова, полученные магнетронным распылением и обладающие газочувствительностью к парам этанола при $38^{\circ} \mathrm{C}$, состоят из нанометровых зерен стержневидной формы, ориентированных по нормали к поверхности подложки, а также в них присутствуют поры, пронизываю-

Письма в ЖТФ, 2017, том 43, вып. 11 
щие пленку на всю толщину. Согласно данным АСМ и СЭМ, средний размер зерен вблизи подложки составляет $6 \mathrm{~nm}$, возрастая до $23 \mathrm{~nm}$ на поверхности, при этом распределение зерен по размерам соответствует нормальному логарифмическому распределению с несколькими центрами распределений, соотносящихся между собой как небольшие целые числа, например, $1: 2$ или $1: 2: 4$, что свидетельствует о срастании зерен между собой.

Малый размер зерна, развитая поверхность, электрический контакт между зернами и наличие пор, пронизывающих поверхность, способствуют снижению сопротивления пленки при комнатной температуре и росту чувствительности к парам этанола. Тогда как пленки оксида олова с большим размером зерна обладают высоким сопротивлением при комнатной температуре, что делает их непригодными для практического использования.

Также мы полагаем, что диаметр зерна $6 \mathrm{~nm}$ является критическим при данных параметрах напыления (мощность $100 \mathrm{~W}$ ). Поэтому, изменяя технологические параметры процесса формирования пленки, такие как энергия бомбардировки подложки, плотность потока осаждаемого вещества и т.п., можно управлять критическим размером зародышей и, как следствие, параметрами пленки, в том числе сопротивлением и чувствительностью к газам.

Исследование выполнено при финансовой поддержке РФФИ в рамках научных проектов № 16-38-00633 мол_а, № 16-07-00821 и при поддержке Совета по грантам Президента РФ (СП-677.2015.4).

\section{Список литературы}

[1] Das S., Jayaraman V. // Prog. Mater. Sci. 2014. V. 66. P. 112-255.

[2] Batzill M., Diebold U. // Prog. Surf. Sci. 2005. V. 79. N 2. P. 47-154.

[3] Seal S., Shukla S. // JOM. 2002. V. 54. N 9. P. 35-38.

[4] Choi K.J., Jang H.W. // Sensors. 2010. V. 10. N 4. P. 4083-4099.

[5] Llobet E. // Sens. Actuat. B: Chemical. 2013. V. 179. P. 32-45.

[6] Arafat M.M. et al. // Sensors. 2012. V. 12. N 6. P. 7207-7258.

[7] Rembeza S., Voronov P., Rembeza E. // Sens. Transducers J. 2010. V. 122. P. 46-54.

[8] Sberveglieri G. et al. // Sens. Actuat. B: Chemical. 1992. V. 8. N 1. P. 79-88.

[9] Anders A. // Thin Solid Films. 2010. V. 518. N 15. P. 4087-4090.

Письма в ЖТФ, 2017, том 43, вып. 11 
[10] Синев И.В. Температурная зависимость сопротивления тонкопленочных резисторов на основе диоксида олова: Автореф. дис. ... канд. физ.-мат. наук. Саратов, 2014. $18 \mathrm{c}$.

[11] Симаков В.В., Синев И.В., Смирнов А.В. // Нанотехника. 2011. № 3. С. $45-$ 46.

[12] Palmer J.E., Thompson C.V., Smith H.I. // J. Appl. Phys. 1987. V. 62. N 6. P. 2492-2497.

Письма в ЖТФ, 2017, том 43, вып. 11 